\title{
Research on Strategies in Response to College Network Public Opinion from the Perspective of Crisis Management
}

\author{
Jiang Yang ${ }^{1, a}$ \\ ${ }^{1}$ Jinan Campus, State Grid of China Technology College, Jinan, Shandong, China \\ a109029743@qq.com \\ * Jiang Yang
}

Keywords: College Network Public Opinion, Crisis Management, Response Strategies

\begin{abstract}
Under the background of profound social transformation and development, colleges have been the high incidence zone of network public opinion crisis in recent years. It becomes necessary and urgent for colleges to study the strategies on how to handle network public opinion from the perspective of crisis management. This paper expounds the characteristics of college network public opinion, analyzes the necessity of crisis management for college network public opinion, and explores the strategies in response to college network public opinion in aspects of working mechanism, early warning, educational guidance and crisis response.
\end{abstract}

\section{Introduction}

With the rapid development of the Internet, network media have become one of the main carriers of public opinion. As the aboriginal inhabitants of the Internet world, college students are more willing to express their views on the platform of Internet. The particularity of the college students group highlights the characteristics of activeness, irrationality and insecurity of the college network public opinion. Negative college network public opinion, if not properly dealt with, may evolve into college public opinion crisis "which has a negative effect on the students as well as the image and reputation of the college in an urgent need of guidance and disposal " [1]. While at present, some colleges are still weak in managing network public opinion, which is clearly shown in their lack of crisis management to handle network public opinion. Therefore, it is of theoretical and realistic significance to study the strategies on how to handle college network public opinion from the perspective of crisis management.

\section{The characteristics of college network public opinion}

"Public opinion", first mentioned by Lippmann in The Public Opinion, refers to views about some facts formed through moral interpretation and organization [2]. As the Internet, the fourth type of media following after newspapers, radio, television, gradually played an important role in our life, "network public opinion" evolving from "public opinion" entered our world with its powerful influence.

College network public opinion refers to various ideas, opinions, attitudes, and emotions that the college students group express via the internet regarding campus phenomena, social problems and some other issues that they are concerned about. As an important part of social public opinion, college network public opinion has its own characteristics in such aspects as the subject, the contents and the carrier of opinion as follows. Firstly, the subjects involved are the large quantity of college students who are young, passionate and highly social. They are active in thinking and action, and ready to express their opinions about various phenomena through internet. Meanwhile, some of them are impulsive, weak in self-control, and tend to randomly air their instant views without much thoughtful consideration. Through internet interaction, college students spontaneously form the communication circles where they may unconsciously strengthen one propensity of some opinions, thus forming the 
group polarization effect. Secondly, with the internet as the information carrier, college network public opinion is spread in an alarming space and at an incredible rate, very easy to heat up. The development of new media has greatly accelerated the speed of and expanded the space of information dissemination. Besides, the college students are the "natives" of the Internet society, with strong adhesion to the Internet and extremely influenced by network public opinion[3].As a result, college network public opinion tends to heat up, easy to spread instantaneously and widely. Thirdly, true and false information are mixed together and may be difficult to differentiate from each other. College students have a strong sense of participation, and most of them enjoy communicating information freely on line and off line. Such interaction connects the virtual world with the real world so closely and easily that sometimes it becomes difficult to tell true information from false one.

\section{The necessity of crisis management for college network public opinion}

Compared with general public opinion, college network public opinion shows the characteristics of emotionality, immediacy and insecurity. Sometimes a hot issue report with a kind of emotional views, can become a "fuse" of negative public opinion, able to lead to the butterfly effect, causing students' mood swings, and even bringing adverse impact on the society.

The following is a typical example to illustrate the potential crisis of college network public opinion. A few years ago when colleges and universities first carried out parallel rail charging policy, some students from poor families in a local college owed their college tuition on purpose for they did not well understand the policy, thus restricting the development of the school. The School had no alternative but to issue the local policy specifying that graduation certificates would be deferred for the graduates who did not pay the tuition fee. Unexpectedly, the local policy caused quite a stir in network public opinion in and out of campus, which uniformly condemned the university as "money-oriented", thus exerting a seriously negative influence on the school. From investigation on numerous cases of college internet public opinion, it has been found that some false or bad Internet public opinion information, if not timely or properly managed, will be distorted and augmented in the process of communication, likely to evolve into a crisis, a "stumbling block" to the college's stability and development. Therefore, how to handle university network public opinion becomes a challenge that colleges face in the internet environment

The study of crisis management originated from the large-scale industrial and environmental disasters in the 1980s. Nowadays, "crisis management" has developed into a discipline within the broader context of management consisting of skills and techniques required to identify, assess, understand, and cope with a serious situation, especially from the moment it first occurs to the point that recovery procedures start[4]. This concept also applied in the field of college network public opinion refers to the process by which colleges make use of all relevant resources and take effective measures to deals with the network public opinion that possibly threatens to harm the college or the general public. The potential crisis of college network public opinion and the applicability of crisis management are the reasons behind the necessity of crisis management for college network public opinion.

\section{Strategies in response to College Network Public Opinion}

Colleges should recognize the potential crisis of network public opinion, adopt the method of crisis management, make full use of the university's strength and resources, and take effective strategies in response to network public opinion in aspects of establishing work mechanism, constructing early warning, enhancing educational guidance and improving crisis response, etc..

\subsection{Establishing the work system to raise the management ability}

To implement college public opinion crisis management, it is primary to establish the work system by reinforcing organization guarantee, institution construction and opinion management consciousness. 
In the first place, the college administrative department should establish organizations responsible for network public opinion management and accordingly form the work pattern in which the party committee acts as the head, the propaganda department leads the coordination, the information center conducts information analysis and all related functional departments and various units are actively involved. Secondly, the college needs to formulate feasible institutions within the framework of laws in the country, like the opinion monitoring regulation, the press spokesman system, and the emergency response procedure. Thirdly, the college should carry out empirical studies on the characteristics and response strategies for college network public opinion to improve its adaptation to network public opinion, and strengthen its management ability.

\subsection{Constructing early warning to reduce the occurrence of network public opinion crisis}

Public opinion early warning refers to taking necessary and effective actions to prevent the occurrence of public opinion crisis during the period from the appearance of the crisis symptoms to the outbreak of the crisis[5]. A warning mechanism developed in advance can timely monitor and guide the correct development of internet public opinion. To construct public opinion warning, we should do a good job of network information collection, detection, analysis and warning. Firstly, online information should be collected by monitoring some online communication platforms like campus website, BBS and blogs, QQ group, which provide a lot of information about the students' thought tendency and the real-world problems. Secondly, the collected sensitive information should be detected and analyzed using scientific and technical methods to accurately predict the possibility of crisis occurrence. Thirdly, early warning information should be imparted to the related departments, prompting them to study the countermeasures, thus timely avoiding irrational behaviors of student groups.

\subsection{Strengthening opinion guidance to exert educational function}

Other than establishing the early warning mechanism, we should also strengthen the correct guidance of network public opinion for the purpose of eliminating the potential conflicts and hidden dangers in the bud.

In view of the characteristics of public opinion carried by means of the emerging new media, colleges should give full play to the positive role of public opinion and conduct public opinion guidance through various internet channels. Most important of all, accurate information should be provided through news media, network and all kinds of activities to meet the teachers and students' right to know the truth, as well as to eliminate uncertainty, confusion, misunderstanding and rumors. Let us also take the above mentioned local college as an example. The college which was accused as money-oriented, timely published an article entitled "Giving more understanding to colleges and universities", which was reprinted in the school newspaper and the campus network BBS. This article promoted the national policy, explained the challenges and difficulties that colleges and universities faced, and raised an argument that "students have right to get their graduation certificates just as they have obligations to pay the tuition fee." Most students were willing to take this view, some of some leaving messages on the internet that they didn't know the country's policies, and many of them agreeing that the college's explanation made perfect sense." In this way, the college successfully guided the network public opinions in appropriate manner that the doubts were solved and students were convinced and bound together. In addition, we should also establish long-term mechanism of public opinion guidance, with engaging contents and educational effect. Under the guidance of "what kind of people to cultivate and how to cultivate them", we conduct an in-depth education of outlook on world, life and values through classroom teaching and various campus media. According to the principle of the public opinion elasticity, perseverely mobilizing and developing the correct public opinion among students will inspire them to recognize the truth, and lead the main body of wrong public opinion to the field of correct opinion. 


\subsection{Improving emergency response to effectively resolve the crisis}

Last but not least, it is necessary to improve the opinion emergency treatment mechanism following the principle of "quick response and proper treatment". Upon the occurrence of public opinion crisis, it is necessary to respond quickly, control the situation as much as possible, curb the vicious spread of incorrect information among students, and minimize the negative impact of the crisis. The emergency group should step forward in the first time to deal with the urgent situation. It is important for the press spokesmen to release accurate and authoritative information through the media within two hours to master the initiative of public opinion. When necessary, they need to instantly publish the latest news, explain the reasons, dispel the rumor, express the college's positive attitude or even take legal measures to in order to stabilize the public mood, reduce the public speculation and minimize the negative impact to the greatest extent. Even after having successfully quelled the crisis, we should also actively settle the remaining problems, and pay close attention to the progress of the whole event to prevent the public opinion crisis from repeating itself. At the same time, we should summarize experiences of emergency disposal in order to improve the emergency crisis mechanism and optimize the network public opinion crisis management

\section{Conclusion}

In a word, the characteristics of college network public opinion increase the occurrence of college network public opinion crisis, thus disrupting the normal teaching order as well as jeopardizing the stability of society. As the administrative workers in colleges, we should strengthen the consciousness of crisis management and actively employ crisis management strategies to cope with college network public opinion. The effective management of network public opinion will help the college to build the harmonious campus as well as achieve the goal of cultivating high-quality talents and serving the society

\section{References}

[1] J.L. Ding, Z.J. Le \& G.S. Wang, A Survey on Internet Public Opinions Crisis Warning in China, Journal of Intelligence, P6, Vol.29 No.10.2010.

[2] L. Walter, Public Opinion, New York: Free Press Paperbacks (Simon \& Schuster), pp. 157-8, 1922.

[3] J. Tao \& Z.M. LEI, An Analysis and Management of Network Public Opinion Crisis in Colleges and Universities, Journal of Zhenjiang University of Technology ( Social Science),p75, Vol. 14 No1,2015.

[4] P. Shrivastava, I.I. Mitroff, D.Miller, and A.Miglani, " Understanding industrial crises". Journal of Management Studies, p.285, 1988.

[5] C.Z. Chen, Y. C. Ao, Research about University Public Opinion Dissemination and Guidance Mechanism under the Network Environment, Journal of Chongqing University ( Social Science Edition), pp.154-159.Vol. 17 No. 2, 2011. 